Jurnal Ilmu Ilmu Agribisnis: Journal of Agribusiness Science, 9(1), Februari 2021

\title{
ANALISIS RANTAI PASOK DAN NILAI TAMBAH AGROINDUSTRI KELANTING DI DESA GANTIMULYO KECAMATAN PEKALONGAN LAMPUNG TIMUR
}

\author{
(Supply Chain Performance Analysis and Added Value of Kelanting Agroindustry in Gantimulyo Village \\ Pekalongan Subdistrict East Lampung Regency)
}

Nanda Aprilia, Muhammad Irfan Affandi, Eka Kasymir

\begin{abstract}
Jurusan Agribisnis, Fakultas Pertanian, Universitas Lampung, Jl. Prof. Dr. Soemantri Brojonegoro No. 1 Bandar Lampung, 35145, e-mail: irfan.affandi@fp.unila.ac.id
\end{abstract}

\begin{abstract}
This study aims to analyze supply chain performanc, and added value in kelanting agroindustry in Gantimulyo Village. This research was conducted at six kelanting agroindustries in Gantimulyo Village, Pekalongan District, East Lampung Regency. Data collection was conducted in February 2019. Data were analyzed using qualitative and quantitative descriptive analysis. Performance measurements were made by comparing indicators on FoodSCOR Card indicators. The calculation of added value used Hayami added value method. The results showed the flow pattern of supply chain started from farmers and agent as the main suppliers of raw materials. The perfomance of kelanting agroindustri showed that the average indicators were good based on indicators comparison of FoodSCOR card. The added value shows a positive value, meaning that kelanting agroindustry is feasible to be developed.
\end{abstract}

Key words: added value, kelanting, supply chain.

\section{PENDAHULUAN}

Sektor industri merupakan salah satu sektor yang memegang peranan penting bagi pembangunan perekonomian nasional. Sektor industri berkontribusi besar bagi pendapatan nasional dan pendapatan daerah, selain itu sektor industri menjadi sektor penyerap tenaga kerja dan menciptakan nilai tambah dari berbagai produk yang dihasilkan. Sektor industri merupakan salah satu strategi yang harus ditempuh untuk mendukung proses pembangunan ekonomi guna mancapai tingkat pendapatan perkapita yang tinggi (Tambunan 2001).

Sektor industri mempunyai peranan sebagai sektor pemimpin, artinya dengan adanya pembangunan industri maka akan memacu sektor lainnya seperti sektor pertanian. Sebagai misal dengan meningkatnya pertumbuhan sektor industri yang pesat akan merangsang pertumbuhan bagi sektor pertanian. Industri sektor pertanian yaitu agroindustri, agroindustri mempunyai peranan penting dalam kegiatan pembangunan daerah, baik dalam sasaran pemerataan pembangunan, pertumbuhan ekonomi. Hal tersebut didukung sumber daya alam pertanian yang mampu menghasilkan berbagai produk olahan (Soekartawi 2001).
Dapat dilihat bahwa industri pengolahan menjadi sektor terbesar kedua setelah sektor pertanian yang berkontribusi terhadap PDRB di Provinsi Lampung. Sektor industri pengolahan tentunya menjadi sektor penting yang perlu dikembangkan karena memiliki kontribusi cukup besar dan diharapkan akan terus mengalami peningkatan. Salah satu bagian dari industri pengolahan yaitu usaha berskala mikro kecil dan menengah atau UMKM. Di Provinsi Lampung usaha berskala mikro kecil dan menegah tersebar di beberapa Kabupaten/Kota.

Kontinuitas pasokan bahan baku sangat diperlukan agar agroindustri bisa beroperasi sepanjang tahun. Pengadaan bahan baku untuk industri kelanting sendiri masih banyak mengalami beberapa hambatan seperti cuaca yang tidak menentu menyebabkan produksi ubi kayu mengalami penurunan. Komoditas ubi kayu juga bersifat musiman, pada musim panen suplai ubi kayu relatif berlimpah, namun ketika bukan musim panen suplai ubi kayu terbatas, tentunya bahan baku yang tersedia untuk agroindustri kelanting relatif sedikit. Sementara permintaan konsumen relatif tetap bahkan meningkat dan agroindustri harus tetap melakukan produksi untuk memenuhi permintaan pasar. 
Tanaman ubi kayu merupakan bahan makanan potensial masa depan dalam tatanan pengembangan agribisnis dan agroindustri. Semakin tinggi harga ubi kayu, maka semakin sedikit jumlah yang diminta dan sebaliknya semakin rendah harga ubi kayu maka semakin banyak jumlah yang diminta. Kekuatan permintaan dan penawaran ini mempengaruhi suatu harga ubi kayu tersebut (Sari 2013).

Fluktuasi suplai bahan baku juga dicerminkan oleh fluktuasi harga komoditas. Beberapa hambatan tersebut mempengaruhi pengadaan bahan baku dari pemasok sehingga akan mengganggu bahkan menghambat produksi kelanting. Permintaan kelanting dari konsumen yang terus meningkat, kadang-kadang tidak seluruhnya terpenuhi karena kendala persediaan bahan baku. Selama ini beberapa agroindustri kelanting di Desa Gantimulyo memperoleh bahan baku dari petani. Dengan demikian, dalam usaha agroindustri kelanting tentu saja melibatkan berbagai unit-unit pengambil keputusan, baik yang bergerak pada proses bahan baku maupun pada produk hasil olahan yang secara keseluruhan terancang dalam sebuah sistem rantai pasok.

Manajemen rantai pasok berupaya mengintegrasikan seluruh komponen-komponen yang terlibat dalam aliran bahan berdasarkan umpan balik dan informasi. Integrasi dilakukan melalui pendekatan lintas fungsional dengan mengelola aliran bahan baku masuk ke pabrik untuk diolah dan aliran produk jadi keluar perusahaan sampai diterima pelanggan akhir. Wujud dari pemasok, pengolah, distributor, pengecer, dan pelanggan dapat diinterpretasikan sesuai dengan cakupan sistem yang dipelajari (Hadiguna 2016).

Rantai pasok sangat berperan penting bagi agroindustri kelanting di Desa Gantimulyo Kecamatan Pekalongan Kabupaten Lampung Timur terkait hubungannya dengan berbagai unit unit pengambil keputusan yang mana akan berpengaruh pada kegiatan produksi pada agroindustri tersebut. Pengolahan ubi kayu menjadi kelanting merupakan pengelolaan bahan mentah yang akan ditransformasikan menjadi produk yang siap digunakan dan memiliki nilai tambah. Nilai tambah merupakan penambahan nilai suatu produk sebelum dilakukan proses produksi dan setelah dilakukan proses produksi.
Pengolahan ubi kayu menjadi kelanting adalah untuk meningkatkan keawetan dan meningkatkan rasa produk sehingga layak untuk dikonsumsi dan memiliki nilai jual yang tinggi di pasaran. Berdasarkan uraian di atas perlu untuk dilakukan pengukuran kinerja rantai pasok, hal tersebut untuk mengetahui penyediaan bahan baku hingga sampai ke tangan konsumen dan mengevaluasi apakah tujuan akhir agroindustri telah tercapai atau belum tercapai, selain itu dilakukannya perhitungan nilai tambah untuk mengetahui nilai tambah yang dihasilkan oleh produk. Adapun tujuan dari penelitian ini yaitu mengetahui kinerja rantai pasok komoditas pada agroindustri kelanting di Desa Gantimulyo, dan mengetahui nilai tambah dihasilkan oleh agroindustri kelanting di Desa Gantimulyo.

\section{METODE PENELITIAN}

\section{Lokasi, Sampel, dan Data}

Penentuan lokasi penelitian dilakukan secara sengaja (purposive) yaitu di Desa Gantimulyo Kecamatan Pekalongan Kabupaten Lampung Timur. Pemilihan lokasi ini dilakukan dengan pertimbangan bahwa daerah ini merupakan sentra agroindustri ubi kayu yang diolah menjadi produk olahan klanting di Kecamatan Pekalongan Lampung Timur. Pengambilan responden pelaku agroindustri kelanting dilakukan dengan cara sensus. Menurut Arikunto (2002), apabila subjek penelitian kurang dari 100 unit (orang), maka lebih baik diambil semua sehingga penelitiannya merupakan penelitian populasi. Pelaku agroindustri kelanting yang menjadi responden berjumlah 6 yang semuanya ada di Desa Gantimulyo.

Metode penelitian yang digunakan dalam penelitian ini adalah metode studi kasus pada agroindustri kelanting di Desa Gantimulyo Kecamatan Pekalongan Kabupaten Lampung Timur. Penelitian ini menggunakan data primer dan data sekunder. Data primer diperoleh melalui wawancara langsung dengan petani ubi kayu, pelaku agroindustri kelanting, pedagang kelanting, dan konsumen kelanting dengan menggunakan kuesioner. Data sekunder diperoleh dari lembaga/instansi terkait seperti Badan Pusat Stastistik, Dinas Koperasi dan UMKM Provinsi Lampung, serta Dinas Perindustrian dan Perdagangan Kabupaten Lampung Timur mengenai jumlah pelaku agroindustri, identitas agroindustri, dan pustaka lainnya yang berhubungan dengan penelitian ini. 


\section{Metode Analisis}

\section{Analisis Kinerja Rantai Pasok}

Analisis sistem rantai pasok digunakan untuk menjawab tujuan pertama, yaitu untuk mengetahui kinerja rantai pasok pada agroindustri kelanting. Rantai pasok merupakan sebuah sistem yang menghubungkan antara pemasok bahan baku, agroindustri, pedagang dan konsumen. Mengukur kinerja rantai pasok pada agroindustri kelanting. Indikator yang digunakan dalam pengukuran kinerja ubi kayu menjadi kelanting didasarkan pada matriks kerja SCOR (Supply Chain Operation Refference), SCOR meliputi reliability, responsiveness, flexibility, cost, dan asset (Setiawan 2011).

SCOR didasarkan pada tiga hal, yakni pemodelan proses, pengukuran performa atau kinerja rantai pasok, dan penerapan best practices (Marimin dan Maghfirudin 2010).

\section{Analisis Nilai Tambah}

Menurut Hayami (1987), nilai tambah adalah pertambahan nilai suatu komoditi karena adanya perlakuan yang diberikan pada komoditi yang bersangkutan. Prosedur perhitungan nilai tambah pada agroindustri kelanting di Desa Gantimulyo Kecamatan Pekalongan Kabupaten Lampung Timur menurut Hayami dapat dilihat pada Tabel 1.

Tabel 1. Prosedur perhitungan metode Hayami

\begin{tabular}{lc}
\hline \multicolumn{1}{c}{ Variabel } & Nilai \\
\hline Output $(\mathrm{Kg} /$ bulan $)$ & $\mathrm{A}$ \\
Bahan baku(Kg/bulan) & $\mathrm{B}$ \\
Tenaga Kerja (HOK/bulan) & $\mathrm{C}$ \\
Faktor Konversi & $\mathrm{D}=\mathrm{A} / \mathrm{B}$ \\
Koefisien Tenaga Kerja & $\mathrm{E}=\mathrm{C} / \mathrm{B}$ \\
Harga Output & $\mathrm{F}$ \\
Upah Rata-rata & $\mathrm{G}$ \\
Tenaga Kerja (Rp/HOK) & $\mathrm{H}$ \\
Harga bahan baku & $\mathrm{I}$ \\
Sumbangan input lain & $\mathrm{J}=\mathrm{D} \times \mathrm{F}$ \\
Nilai Output & $\mathrm{K}=\mathrm{J}-\mathrm{I}-\mathrm{H}$ \\
a. Nilai Tambah & $\mathrm{L}=(\mathrm{K} / \mathrm{J}) \times 100 \%$ \\
b. Rasio Nilai Tambah & $\mathrm{M}=\mathrm{E} \times \mathrm{G}$ \\
a. Imbalan Tenaga Kerja & $\mathrm{N}=(\mathrm{M} / \mathrm{K}) \times 100(\%)$ \\
b. Bagian Tenaga Kerja & $\mathrm{O}=\mathrm{K}-\mathrm{M}$ \\
a. Keuntungan & $\mathrm{P}=\mathrm{O} / \mathrm{K} \times 100(\%)$ \\
b. Tingkat Keuntungan & $\mathrm{Q}=\mathrm{J}-\mathrm{H}$ \\
Margin Keuntungan & $\mathrm{R}=\mathrm{O} / \mathrm{Q} \times 100 \%$ \\
a. Keuntungan & $\mathrm{S}=\mathrm{M} / \mathrm{Q} \times 100 \%$ \\
b. Tenaga Kerja & $\mathrm{T}=\mathrm{I} / \mathrm{Q} \times 100 \%$ \\
c. Input Lain & \\
\hline Sumber : Hayami (1987) &
\end{tabular}

Kriteria nilai tambah adalah :

1. Jika NT $>0$, berarti pengembangan agroindustri kelanting memberikan nilai tambah hasilnya positif.

2. Jika NT $<0$, berarti pengembangan agroindustri kelanting tidak memberikan nilai tambah hasilnya negatif.

\section{HASIL DAN PEMBAHASAN}

\section{Keadaan Umum Responden}

Responden pada penelitian ini berjumlah 54 orang yang terdiri dari 8 petani ubi kayu, 4 orang agen ubi kayu, 6 orang pelaku agroindustri kelanting, 10 orang agen kelanting, 8 orang pedagang kelanting, 10 orang pengecer kelanting, dan 8 orang konsumen kelanting. Usia responden pelaku rantai pasok pada agroindustri kelanting di Desa Gantimulyo termasuk dalam golongan usia produktif, sehingga cukup potensial. Tingkat pendidikan responden sudah cukup baik karena rata-rata pendidikan terakhirnya adalah tingkat SMA. Pengalaman usaha responden yaitu rata-rata selama 5-16 tahun.

\section{Analisis Kinerja Rantai Pasok}

Berdasarkan rincian kinerja rantai pasok pada setiap anggota rantai pasok agroindustri kelanting di Desa Gantimulyo, mulai dari petani ubi kayu, agen ubi kayu dan agroindustri kelanting. Aliran ubi kayu yang menjadi fokus dalam penelitian ini, yaitu yang menjadi bahan baku agroindustri kelanting. Aliran produk berawal dari petani ubi kayu, kemudian agen ubi kayu, selanjutnya ke agroindustri, dan berakhir pada berbagai konsumen kelanting. Kinerja yang diukur adalah kinerja petani ubi kayu, agen ubi kayu dan agroindustri kelanting. Kinerja rantai pasok ubi kayu pada agroindustri.

Menurut Hasibuan (2002), kinerja suatu proses atau sistem dapat dilihat dari kinerja rantai pasok secara keseluruhan. Kinerja dari setiap anggota rantai pasok akan sangat mempengaruhi kinerja rantai pasok sendiri. Hal tersebut disebebkan jika terdapat kinerja yang kurang baik pada salah satu anggota rantai pasok, akan dapat mempengaruhi aliran barang sehingga dapat menyebabkan rantai pasok berjalan kurang baik. kelanting di Desa Gantimulyo dapat dilihat pada Tabel 2. 
Jurnal Ilmu Ilmu Agribisnis: Journal of Agribusiness Science, 9(1), Februari 2021

Tabel 2. Rincian nilai dan kriteria kinerja rantai pasok ubi kayu pada petani, agen dan agroindustri kelanting

\begin{tabular}{|c|c|c|c|c|c|c|c|}
\hline \multirow{2}{*}{ Indikator } & \multirow{2}{*}{$\begin{array}{c}\text { Target } \\
\text { Untuk } \\
\text { Mencapai } \\
\text { Kriteria } \\
\text { Baik } \\
\end{array}$} & \multicolumn{2}{|c|}{ Petani } & \multicolumn{2}{|c|}{ Agen } & \multicolumn{2}{|c|}{ Agroindustri } \\
\hline & & Nilai & Kriteria & Nilai & Kriteria & Nilai & Kriteria \\
\hline Lead Time Pemenuhan Pesanan (Jam) & $\leq 72$ jam & 8,40 & Baik & 4,70 & Baik & 72,25 & $\begin{array}{c}\text { Kurang } \\
\text { baik }\end{array}$ \\
\hline Siklus Pemenuhan Pesanan (Jam) & $\leq 336$ jam & 2,70 & Baik & 2,10 & Baik & 6,42 & Baik \\
\hline Fleksibilitas Rantai Pasok (Jam) & $\leq 240$ jam & 0,00 & Baik & 0,00 & Baik & 72,00 & Baik \\
\hline Cash to Cash Cycle Time ( Hari) & $\leq 696$ jam & 1,00 & Baik & 1,00 & Baik & 1,00 & Baik \\
\hline Persediaan Harian (hari) & $\leq 552$ jam & 0,00 & Baik & 0,00 & Baik & 3,00 & Baik \\
\hline Kinerja Pengiriman (\%) & $\geq 95 \%$ & 100,00 & Baik & 90,00 & Baik & 98,04 & Baik \\
\hline Pemenuhan Pesanan $(\%)$ & $\geq 88 \%$ & 100,00 & Baik & 100,00 & Baik & 100,00 & Baik \\
\hline Kesesuaian dengan standar (\%) & $\geq 88 \%$ & 98,95 & Baik & 99,35 & Baik & 100,00 & Baik \\
\hline
\end{tabular}

Baik atau tidaknya kinerja rantai pasok ditunjukan oleh keselarasan anggota rantai pasok dalam melakukan aktivitasnya. Berdasarkan Tabel 2, rantai pasok ubi kayu pada agroindustri kelanting di Desa Gantimulyo Kecamatan Pekalongan Kabupaten Lampung Timur memiliki kinerja yang baik secara keseluruhan yaitu telah mencapai target nilai yang ditetapkan pada FoodSCOR card. Hasil penelitian ini sejalan dengan penelitian Sari (2018) yaitu Rantai Pasok dan Nilai Tambah Keripik Nangka Pada Agroindustri Keripik Panda Alami di Kecamatan Gedong Tataan Kabupaten Pesawaran, secara keseluruhan kinerja rantai pasok agroindustri tersebut baik

\section{Analisis Nilai Tambah}

Menurut Hayami (1987), nilai tambah adalah pertambahan nilai suatu komoditi karena adanya perlakuan yang diberikan pada komoditi yang bersangkutan. Kegiatan agroindustri mengolah ubi kayu menjadi kelanting mengakibatkan bertambah nilai komoditi tersebut. Nilai tambah juga merupakan selisih harga ubi kayu dan kelanting yang diperoleh agroindustri.

Berdasarkan Tabel 2, rata-rata nilai tambah yang diperoleh agroindustri kelanting di Desa Gantimulyo. Besarnya rata-rata output yang dihasilkan diperoleh nilai faktor konversi sebesar 0,24 yang artinya dari satu kilogram ubi kayu menghasilkan 0,24 kilogram kelanting. Pembuatan satu kilogram kelanting, rata-rata sumbangan input lain yang digunakan adalah Rp. 1.118,00 Nilai ini diperoleh dari jumlah rata-rata. Pembagian biaya total rata-rata sumbangan input lain dengan jumlah rata-rata output yang dihasilkan sebesar 743,00 kilogram kelanting.

Berdasarkan Tabel 3, keuntungan yang diperoleh dari proses pengolahan bahan baku ubi kayu menjadi kelanting sebesar Rp. 335,00 dengan tingkat keuntungan sebesar 31,30 persen dari nilai produk.

Hasil analisis ini sejalan dengan penelitian Pertiwi (2015) tentang nilai tambah pengendalian bahan baku dan pendapatan usaha pada kub Bina Sejahtera di Kelurahan Kangkung Kecamatan Bumi Waras Kota Bandar Lampung yang memiliki nilai tambah positif, artinya usaha layak untuk dijalankan.

Nilai keuntungan merupakan selisih nilai tambah dengan imbalan tenaga kerja. Produksi kelanting menghasilkan imbalan tenaga kerja sebesar $\mathrm{Rp}$ 736,00 , sementara keuntungan yang diperoleh yaitu sebesar $\mathrm{Rp} 335,00$ dengan bagian keuntungan sebesar 31,30 persen dari nilai output. Hal tersebut menjelaskan bahwa usaha pengolahan kelanting di Desa Gantimulyo termasuk dalam kategori agroindustri padat karya, karena nilai balas jasa pemilik faktor produksi tinggi pada tenaga kerja dibandingkan dengan keuntungan. Artinya, agroindustri tersebut menyerap tenaga kerja di sekitar lingkungan agroindustri.

Hasil penelitian ini sejalan dengan penelitian Anggraeni (2017) yaitu agroindustri tempe di Kabupaten Pesawaran bersifat padat karya. Hal tersebut dapat dilihat dari nilai balas jasa pemilik terhadap tenaga kerja lebih besar dibandingkan nilai keuntungan. Hasil penelitian ini juga mendukung hasil penelitian Agustina (2015) yaitu harga pokok produksi, nilai tambah, dan prospek pengembangan agroindustri marning di Kecamatan Gedong Tataan Kabupaten Pesawaran yang menyatakan untuk meningkatkan nilai tambah dan keuntungan produsen harus melakukan proses produksi yang lebih efisien. 
Tabel 3. Analisis nilai tambah produk kelanting di Desa Gantimulyo

\begin{tabular}{|c|c|c|}
\hline \multirow{2}{*}{$\begin{array}{l}\text { Variabel } \\
\text { Output, input, dan harga }\end{array}$} & \multicolumn{2}{|c|}{ Nilai } \\
\hline & & \\
\hline Output (Kg/Minggu) & A & 743,00 \\
\hline Bahan baku(Kg/Minggu) & $\mathrm{B}$ & $3.083,00$ \\
\hline Tenaga Kerja & & \\
\hline (HOK/Minggu) & $\mathrm{C}$ & 46,20 \\
\hline Faktor Konversi & $\mathrm{D}=\mathrm{A} / \mathrm{B}$ & 0,24 \\
\hline Koefisien Tenaga Kerja & $\mathrm{E}=\mathrm{C} / \mathrm{B}$ & 0,01 \\
\hline Harga Output & $\mathrm{F}$ & $15.000,00$ \\
\hline Upah Rata-rata Tenaga & & \\
\hline Kerja $(\mathrm{Rp} / \mathrm{HOK})$ & $\mathrm{G}$ & $48.595,00$ \\
\hline Harga bahan baku & $\mathrm{H}$ & $1.400,00$ \\
\hline Sumbangan input lain & I & $1.118,00$ \\
\hline a. minyak & & 401,00 \\
\hline b. solar & & 44,00 \\
\hline c. Kayu bakar & & 38,00 \\
\hline d. Kemasan (plastik) & & 213,00 \\
\hline e. $\log 0$ & & 41,00 \\
\hline f. Penyedap rasa & & 29,00 \\
\hline g. Bubuk Balado & & 141,00 \\
\hline h. Pemanis & & 13,00 \\
\hline i. Bawang Putih & & 80,00 \\
\hline j. Garam & & 31,00 \\
\hline k. Biaya transportasi & & 33,00 \\
\hline 1. Biaya Listrik & & 29,00 \\
\hline Nilai Output & $\mathrm{J}=\mathrm{D} \times \mathrm{F}$ & $3.589,00$ \\
\hline a. Nilai Tambah & $\begin{aligned} \mathrm{K} & =\mathrm{J}-\mathrm{I}-\mathrm{H} \\
\mathrm{L} & =(\mathrm{K} / \mathrm{J}) \mathrm{x}\end{aligned}$ & $1.071,00$ \\
\hline b. Rasio Nilai Tambah & $100 \%$ & 29,84 \\
\hline a. Imbalan Tenaga Kerja & $\begin{array}{c}M=E \times G \\
N=(M / K) \times\end{array}$ & 736,00 \\
\hline b. Bagian Tenaga Kerja & $100(\%)$ & 68,70 \\
\hline a. Keuntungan & $\mathrm{O}=\mathrm{K}-\mathrm{M}$ & 335,00 \\
\hline b. Tingkat Keuntungan & $\begin{array}{c}\mathrm{P}=\underset{\mathrm{O} / \mathrm{K} \times 100}{(\%)}\end{array}$ & 31,30 \\
\hline $\begin{array}{l}\text { Balas Jasa Pemilik } \\
\text { Faktor-faktor Produksi }\end{array}$ & & \\
\hline Margin Keuntungan & $\begin{array}{c}Q=J-H \\
R=O / Q \times 100\end{array}$ & $2.189,00$ \\
\hline a. Keuntungan & $\mathrm{S}=\mathrm{M} / \mathrm{Q} \mathrm{x}$ & 15,30 \\
\hline b. Tenaga Kerja & $100 \%$ & 33,60 \\
\hline c. Input Lain & $\mathrm{T}=\mathrm{I} / \mathrm{Q} \times 100 \%$ & 51,10 \\
\hline
\end{tabular}

\section{KESIMPULAN}

Aliran rantai pasok pada agroindustri kelanting dimulai dari petani ubi kayu, agen ubi kayu, dan agroindustri, kemudian setelah menjadi kelanting di pasarkan ke berbagai konsumen. Aliran barang dari satu anggota rantai pasok ke anggota yang lainnya memiliki kriteria kinerja yang baik dengan pemenuhan pesanan di atas 88,00 persen, persediaan harian di bawah 552,00 jam, fleksibilitas di bawah 240,00 jam, lead time pemenuhan pesanan untuk petani dan agen ubi kayu di bawah 72,00 jam, siklus pemenuhan pesanan di bawah 336,00 jam, kinerja pengiriman di atas 95,00 persen, kesesuaian standar di atas persen, dan perputaran uang di bawah 696,00 jam. Hal ini berdasarkan pengukuran indikator input dan output dengan kriteria FoodSCOR Card pada setiap anggota rantai pasok. Agroindustri kelanting memiliki nilai tambah yang positif, artinya agroindustri kelanting menguntungkan, agroindustri kelanting di Desa Gantimulyo dikategorikan padat karya, artinya agroindustri menyerap tenaga kerja di sekitar agroindustri.

\section{DAFTAR PUSTAKA}

Agustina DR, Ismono RH, dan Nugraha A. 2015. Harga pokok produksi, nilai tambah, dan prospek pengembangan agroindustri marning di Kecamatan Gedong Tataan Kabupaten Pesawaran. Jurnal Ilmu Ilmu Agribisnis, 3 (2): 157-164.

http://jurnal.fp.unila.ac.id/index.php/JIA/articl e/view/1034/939. [28 Agustus 2019].

Anggraeni TS, Lestari DAH, dan Indriani Y. 2017. Keragaan agroindustri tempe anggota Primkopti Kabupaten Pesawaran. Jurnal Ilmu Ilmu Agribisnis, 3 (5): 275-282. http://jurnal.fp.unila.ac.id/ index.php/JIA/article/view/1640/1466. Juni 2019].

Arikunto S. 2002. Metodologi Penelitian Suatu Pendekatan Proposal. Rineka Cipta. Jakarta.

Bolstorff P, dan Rosenbaum R. 2011. Supply Chain Excellence: A Handbook for Dramatic Improvement Using the SCOR Model (US). Prentice Hall. New York.

Hadiguna RA. 2016. Manajemen Rantai Pasok Agroindustri. Andalas University Press. Padang.

Hasibuan M. 2002. Manajemen Sumber Daya Manusia. Bumi Aksara. Jakarta.

Hayami Y, Thosinori M, dan Masdjidin S. 1987. Agricultural Markerting and Processing in Upland Java. A prospectif From A Sunda Village. Bogor.

Marimin dan Maghfiroh N. 2010. Aplikasi Teknik Pengambilan Keputusan dalam Manajemen Rantai Pasok. IPB. Press Bogor.

Pertiwi KA, Affandi MI, dan Kasymir E. 2015. Nilai tambah pengendalian bahan baku dan pendapatan usaha pada kub Bina Sejahtera di Kelurahan Kangkung Kecamatan Bumi Waras Kota Bandar Lampung. Jurnal Ilmu Ilmu Agribisnis, $\quad 3 \quad$ (1): 26-31. http://jurnal.fp.unila.ac.id.id/index.p 
Jurnal Ilmu Ilmu Agribisnis: Journal of Agribusiness Science, 9(1), Februari 2021

hp/JIA/article/view/1014/919. [28 Agustus 2019].

Sari SI, Ismono RH, dan Nurmayasari I. 2013. Pengaruh kebijakan pemerintah terhadap pelaku ekonomi ubi kayu di Provinsi Lampung. Jurnal Ilmu Ilmu Agribisnis, 1 (1): 73-79.

http://jurnal.fp.unila.ac.id/index.phpJIA/articl e/view/1015/920. [28 Agustus 2019].

Sari RY, Hasyim AI, dan Widjaya S. 2018. Rantai Pasok dan nilai tambah keripik nangka pada Agroindustri Keripik Panda Alami di Kecamatan Gedong Tataan Kabupaten Pesawaran. Jurnal Ilmu Ilmu Agribisnis, 6 (3): 257-262.
http://jurnal.fp.unila.ac.id/index.php/JIA/articl e/view/3022/2411. [20 Juni 2019].

Setiawan A. 2011. Studi peningkatan kinerja manajemen rantai pasok sayuran dataran tinggi di Jawa Barat. Jurnal Teknologi Pertanian: 31 (1): 60-70. https://jurnal. ugm.ac.id/agritech/article/view/9727. [tanggal 11 Juli 2019].

Soekartawi. 2001. Pengantar Agroindustri. Raja Grafindo Persada. Jakarta.

2003. Prinsip Dasar Ekonomi Pertanian: Teori dan Aplikasinya. Rajawali Press. Jakarta.

Tambunan TH. 2001. Perekonomian Indonesia. Ghalia. Jakarta. 